\title{
Captive Bred, Adult Giant Clams Survive Restoration in the Wild in Seychelles, Indian Ocean
}

\author{
Sarah Frias-Torres ${ }^{1,2 *}$ \\ ${ }^{1}$ Nature Seychelles, Island Conservation Centre, Praslin, Seychelles, ${ }^{2}$ Smithsonian Marine Station, Fort Pierce, FL, USA
}

OPEN ACCESS

Edited by:

E. Christien Michael Parsons, George Mason University, USA

Reviewed by:

Rita P. Vasconcelos, Marine and Environmental Sciences

Centre, Portugal

Leslie Cornick

Alaska Pacific University, USA

${ }^{*}$ Correspondence:

Sarah Frias-Torres sfriastorres@gmail.com

Specialty section:

This article was submitted to Marine Conservation and

Sustainability,

a section of the journa Frontiers in Marine Science

Received: 29 December 2016 Accepted: 23 March 2017

Published: 10 April 2017

Citation:

Frias-Torres S (2017) Captive Bred, Adult Giant Clams Survive Restoration in the Wild in Seychelles, Indian

Ocean. Front. Mar. Sci. 4:97. doi: 10.3389/fmars.2017.00097
Coral reef restoration focuses on scleractinian corals, excluding other groups that provide structural complexity to these threatened ecosystems. Giant clams share the role of ecosystem engineers alongside corals in the Indo-Pacific, but overfishing has caused widespread local extinctions. Aquaculture reduces pressure on wild populations and captive bred juveniles have been used to restore extinct populations. However, giant clam restoration has not been attempted before with adults until now. A total of 150 captive bred, adult giant clams (Tridacna maxima), 4-10 years old, shell length 99-198 $\mathrm{mm}$, were relocated to a healthy reef (control site) and a restored reef (treatment site) at a coral reef restoration project in Seychelles, Indian Ocean, in two sequential experiments. The first experiment started in April (calm season, NW Monsoon), deployed 30 clams, 15 per site at $12 \mathrm{~m}$ depth, and lasted 20 weeks. The second experiment started in June (rough season, SE Monsoon), deployed 120 clams, 60 per site at 6 and $12 \mathrm{~m}$ depth, and lasted 11 weeks. T. maxima were measured and double tagged with glue-on shellfish tags prior to deployment. Survival was monitored weekly or biweekly depending on weather conditions. Remote GoPro video cameras confirmed the transplanted T. maxima displayed normal behavior. Survival rates from Kaplan-Meier curves were 3.3-66.7\%. Median survival time was 2 weeks to more than 20 weeks. T. maxima survived 3.3-5 times longer at the treatment site than at the control site in both experiments. T. maxima mortality was a combination of transplant season, predators, byssal re-attachment and wave swells. In the first experiment, mortality was due to octopus predation and 1.8 times higher at the control site than at the treatment site. The control site was an older reef with more octopus dens resulting in higher predation. T. maxima transplanted in April had 1 month to re-attach before the rough season started, but those transplanted in June were mostly dislodged by wave swells. These results show captive bred, adult T. maxima survive restoration in the wild. The potential synergy of jointly restoring corals and giant clams in the Indo-Pacific region is discussed.

Keywords: Tridacna maxima, coral reef restoration, endangered species, mariculture, CITES, IUCN

\section{INTRODUCTION}

Coral reef restoration efforts usually focus on growth and reattachment of reef-building corals, (Precht, 2006) excluding other groups that provide structural complexity to these threatened ecosystems (McMurray and Pawlik, 2009). Giant clams (family Cardiidae, subfamily Tridacninae) live closely associated with coral reefs in the Indo-Pacific region (Lucas, 1988). They share the role 
of ecosystem engineers alongside hermatypic corals by providing topographic relief and calcium carbonate to the reef framework (Cabaitan et al., 2008; Neo et al., 2015). The 13 extant species of giant clams in two genera, Hippopus and Tridacna (Neo et al., 2015), range from smallest Tridacna crocea (maximum shell length, $\left.\mathrm{SL}_{\max }=15 \mathrm{~cm}\right)$ to largest $T$. gigas $\left(\mathrm{SL}_{\max }=140\right.$ cm) (WoRMS Editorial Board, 2017). Unfortunately, giant clam populations have been depleted due to overfishing for meat, shells, and the aquarium trade (Lucas, 1994; Wabnitz et al., 2003; Gomez and Mingoa-Licuanan, 2006), eutrophication, and reef degradation (Newman and Gomez, 2000), in spite of local management efforts, including mariculture (Tisdell and Menz, 1992; bin Othman et al., 2010). Some species are locally extinct in many areas of Southeast Asia and the South Pacific (Tomascik et al., 1997; Wells, 1997; Neo and Todd, 2012). Recently, bans on the elephant ivory trade have increased giant clam fishing, so they fulfill the demand in Asian markets for jewelry and house ornaments (clam shells) and aphrodisiacs (clam meat) (Larson, 2016). Increased giant clam shell trade and poaching also result in widespread coral reef destruction in the South China Sea, as poachers use boat propellers to loosen the giant clams, dragging them through the reef and carving up long stretches of lifeless rubble (Bale, 2016). All giant clam species are threatened throughout much of their geographic range (Lucas, 1994), listed as "vulnerable" under the International Union for Conservation of Nature (IUCN) Red List of threatened species and their trade is regulated by the Convention on International Trade in Endangered Species (CITES) Appendix II (IUCN, 2016; UNEP-WCMC, 2016).

Giant clams are mixotrophic bivalve mollusks capable of primary production through mutualistic symbiosis with zooxanthellae, dinoflagellates of the genus Symbiodinium, living inside their mantle (Jantzen et al., 2008) and secondary production via filter feeding (Jones et al., 1986). They are the largest living bivalves found in close association with coral reefs throughout the Indo-Pacific (Lucas, 1988). With their large size and stunning colors ranging from electric blue, green, pink, and purple to gold, giant clams are equivalents of "charismatic megafauna" that can act as flagship taxa, drawing attention to the ongoing destruction of coral reefs (Soo and Todd, 2014). Giant clams have ecological significance as reef builders, contributing to the calcium carbonate framework of coral reefs (Barker et al., 1988; Gilbert et al., 2006), as food for 75 known predators and a scavenger guild, shelter for juvenile and adult coral reef fish, shell surfaces for epibionts and as hosts for ectoparasites and commensals (Neo et al., 2015). Giant clams are simultaneous hermaphrodites that spawn sperm first and then eggs during a spawning event (Wada, 1952). Sexual maturity is reached earlier in smaller species (e.g., 4 years; Lucas, 1994) and later in larger species (e.g., 10 years in T. gigas; Gomez et al., 2000). Pheromone communication between giant clam individuals initiates synchronized spawning (Waters et al., 2013). In T. gigas, up to $70 \%$ of spawning individuals can signal their nearest neighbor that spawning has begun if located within $9 \mathrm{~m}$, but only $15 \%$ at distances between 20 and $30 \mathrm{~m}$ (Braley, 1984). The distance threshold is considered similar in other tridacnid species (Braley, 1984). When individuals are isolated and beyond the
$30 \mathrm{~m}$ spatial threshold distance, the population is functionally extinct (Guest et al., 2008).

Mariculture linked to restoration (re-stocking) of reefs has been attempted as a solution to manage local giant clam extinctions. Previous captive bred giant clam restoration efforts with Tridacna maxima (Waters et al., 2013), T. derasa (Heslinga et al., 1984), T. squamosa (Guest et al., 2008) and T. gigas (Gomez and Mingoa-Licuanan, 2006) have focused on juvenile individuals, and show a relationship between size at transplant and mortality, where there is a minimum "escape size" from predation in natural habitats, and variability in survival rate depending on size at transplant and duration of experiment. From February-April 1999, an aquaculture facility at Praslin Island, Seychelles, deployed 766, 6-year old, adult Tridacna maxima at $<8 \mathrm{~m}$ depth at Baie Laraie, Curieuse Island, in an attempt to restore the wild giant clam population (A. Hennie, Black Pearl Seychelles, Pers. Comm.). The mortality rate was close to $100 \%$. Lack of a robust experimental design and individual tagging prevented the analysis of restoration failure. From these studies it is unclear whether adult giant clams can survive restoration.

The aim of this study was to investigate the ability of captive bred adult giant clams (Tridacna maxima) to survive restoration in the wild. There were two objectives: (a) to determine the best season to transplant giant clams; and (b) to transplant giant clams to reef sites representing two environmental conditions, a healthy reef (control site) and a restored reef (treatment site), to quantify survival rates over a maximum period of 5 months.

\section{MATERIALS AND METHODS}

\section{Field Settings}

Two giant clam restoration experiments were conducted between April 11, 2014 and September 3, 2014, at a large-scale coral reef restoration project within the marine protected area of Cousin Island Special Reserve, Seychelles, Indian Ocean (Figure 1). A detailed study site description is found elsewhere (MontoyaMaya et al., 2016). Briefly, the site includes a continuous fringing reef on the south-west side of Cousin Island. The reef is $\sim 400 \mathrm{~m}$ long and $30 \mathrm{~m}$ wide, depth range $6.5-13 \mathrm{~m}$. Corals of a $40 \mathrm{~m}$ long section of the reef at its southernmost end ( $\left.4^{\circ} 20^{\prime} 09^{\prime \prime} \mathrm{S}, 55^{\circ} 39^{\prime} 32^{\prime \prime} \mathrm{E}\right)$ survived the 1998 mass coral bleaching event due to the coupling of El Niño and the Indian Ocean Dipole (Spencer et al., 2000; Spalding and Jarvis, 2002), and breakage from the 2004 Indian Ocean Tsunami (Jackson et al., 2005). This section became the control healthy site. Coral cover at this site improved from $<15 \%$ in 2012 to $>35 \%$ in 2014, and is dominated by Acropora (A. appressa, A. cytherea, A. humilis, A. hyacinthus) and Pocillopora (P. grandis and $P$. verrucosa) species. Coral cover in the remainder of the reef was less than 3\% after the 1998 mass coral bleaching and 2004 tsunami. Here, a 50-m long section of the reef, northwest of the control healthy site $\left(4^{\circ} 20^{\prime} 08^{\prime \prime} \mathrm{S}, 55^{\circ} 39^{\prime} 30^{\prime \prime} \mathrm{E}\right)$, became the control degraded site with a mix of consolidated, unconsolidated rubble and sand dominating the substrate. A $150 \mathrm{~m}$ long section of degraded reef north of the control degraded site $\left(4^{\circ} 20^{\prime} 04^{\prime \prime} \mathrm{S}, 55^{\circ} 39^{\prime} 25^{\prime \prime}\right.$ E) was targeted for restoration 

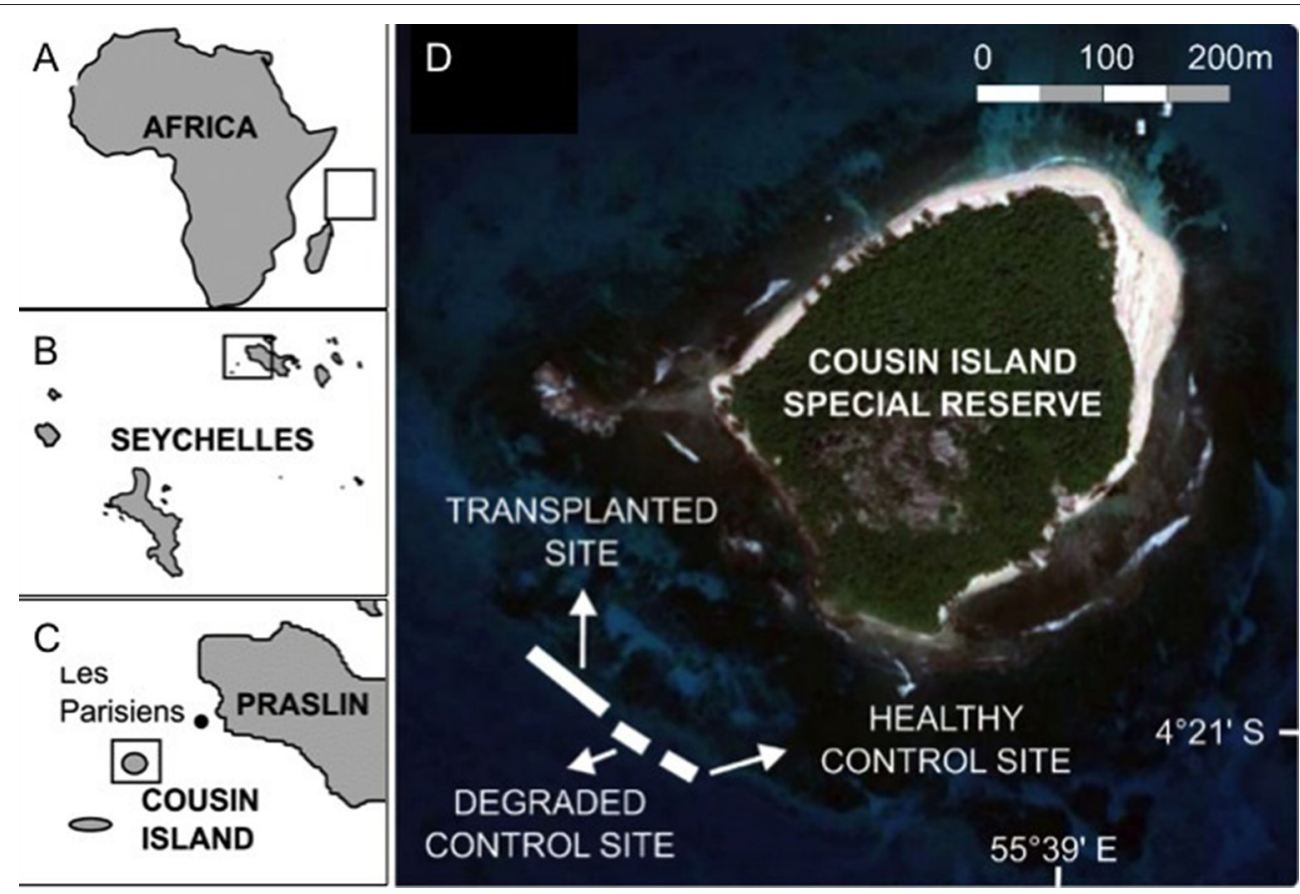

FIGURE 1 | Study area. (A-C) Location of Cousin Island Special Reserve in the Indian Ocean and Seychelles. (D) Square on (C) expanded to show detail of Cousin Island. The coral reef restoration sites (transplanted reef, healthy site and degraded site) are shown. Giant clams, Tridacna maxima were deployed at the healthy site (control) and the coral transplanted site (treatment). From Frias-Torres and van de Geer (2015) under Creative Commons CCBY 4.0 License. No permission was needed for the reproduction of this figure.

through coral transplantation, and became the coral transplanted site (0.52 ha). At this location, a gentle slope (roughly $25^{\circ}$ ) extends to a depth of $13 \mathrm{~m}$. The seabed then flattens out and consists of a mixture of sand and coral rubble interspersed with granite outcroppings (Frias-Torres and van de Geer, 2015). Sites were separated by arbitrarily defined $50 \mathrm{~m}$ buffer zones. From October to early May, the trade winds blow from the northwest (Northwest Monsoon); this is the period of calms in the Seychelles. From late May to October the trade winds blow from the southeast (Southeast Monsoon); this is the period of strong wave swells. A total of 10 different nurserygrown branching/tabular species of corals (Acropora cytherea, A. damicornis, A. formosa, A. hyacinthus, A. abrotanoides, A. lamarki, A. vermiculata, Pocillopora damicornis, $P$. indiania, $P$. grandis and $P$. verrucosa) were cemented at the transplanted site between November 2012 and June 2014 (Montoya-Maya et al., 2016).

During underwater surveys for the coral reef restoration project, one wild giant clam (Tridacna maxima) was found at the control-healthy site (Figure 2). This clam, with SL $=35 \mathrm{~cm}$ (the maximum size for the species) was a survivor of the $1998 \mathrm{El}$ Niño mass bleaching event (Spencer et al., 2000). Based on local traditional knowledge (Travis, 1990; local octopus fishermen Pers. Comm.; A. Hennie, Black Pearl Seychelles, Pers. Comm.), the wild clam survivor confirmed that prior to the 1998 bleaching event, T. maxima inhabited the fringing reef at the project site. Therefore, restoring the giant clam population at Cousin Island was consistent with ecosystem complexity in the past (Suding

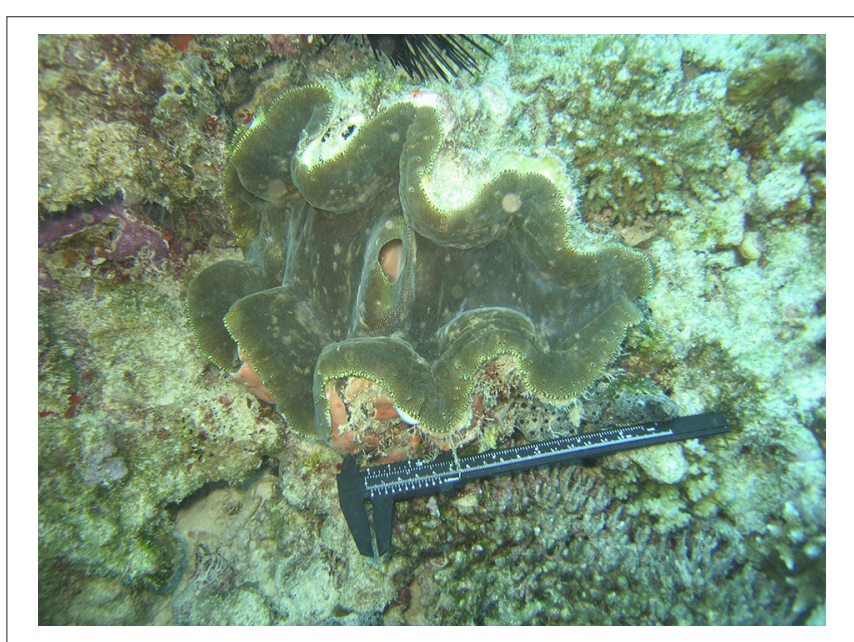

FIGURE 2 | Wild Giant Clam, Tridacna maxima. This giant clam, with shell length $35 \mathrm{~cm}$, was found at the control-healthy site. Photo credit: C. Reveret.

et al., 2015) where corals and giant clams coexisted. When the first giant clam restoration experiments started on April 11, 2014, the coral transplanted site had been modified from a flattenedout degraded state to include 19,745 cemented nursery-grown corals. When the giant clam experiments ended on September 3 , 2014, a total of 24,431 corals had been cemented at the transplanted site. 


\section{Giant Clams}

An aquaculture facility at Praslin Island, named Black Pearl Seychelles, had been growing giant clams T. maxima for the aquarium trade since the 1980s. Their parental stock was recruited from wild clams throughout the islands. The wild clams spawned at the facility, then they were released back to their original locations. The company's clam stock has been self-sustaining ever since.

A total of 150 captive bred giant clams (Tridacna maxima) from second-generation brood stock were donated to this project by Black Pearl Seychelles. These clams had outgrown the ideal size for shipping overseas to the aquarium trade with guaranteed survival on arrival. Clam size ranged from 99 to $198 \mathrm{~mm}$ shell length and they were 4-10 years old (Munro, 1993), having reached sexual maturity (Lucas, 1994). Prior to deployment in the field, each clam was measured and double-tagged with numbered glue-on shellfish Hallprint Tags. The shell length (the maximum antero-posterior dimension of the shell) was measured with longjaw aluminum calipers to the nearest $1 \mathrm{~mm}$. For tagging, each clam was taken out of the flow-through seawater shallow tanks or raceways; the leading edge of each valve was towel dried, and one numbered $8 \times 4 \mathrm{~mm}$ oval glue-on shellfish tag was attached to each valve edge, using Loctite ${ }^{\circledR}$ superglue. Each clam was left out of the water for $5 \mathrm{~min}$ to ensure the glue bonded with both tag and shell, while gently pressing the tag with a cotton swab (Figure 3 ). Since the mantle covers the flat valve edge when giant clams keep their valves open, biofouling is absent, making the valve edge an ideal location for tagging. This is the first time glue-on shellfish tags have been used to identify individual giant clams.

To minimize damage during transportation to the deployment sites, tagged clams were taken out of the raceways, their valves were kept closed with elastic hair bands, and they were held

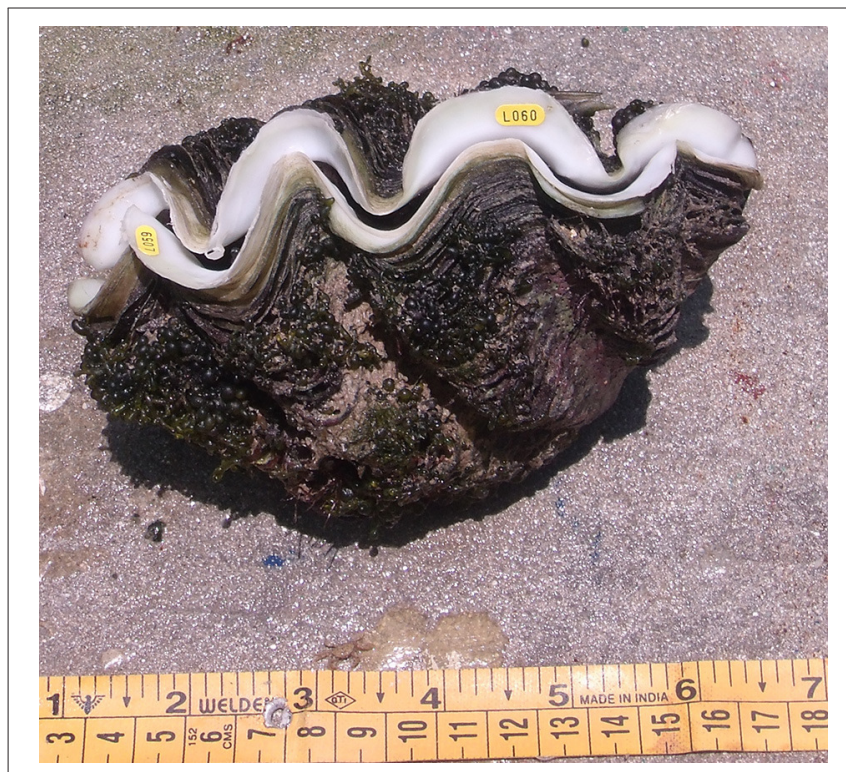

FIGURE 3 | Tagged Giant Clam, Tridacna maxima. Giant Clams were double-tagged by using glue-on shellfish Hallprint Tags on the edge of their valves. Here clam L059/L060 is shown. inside plastic fruit crates with rolled up beach towels. This setup avoided damaging vibrations and accidental opening of clam shells during boat transportation. Before deployment, hair bands and towels were removed and the crate with the clams was deployed underwater. The crate was held in place on the seabed by rope and weights. From there, each clam was moved to its transplant location. The time spent from raceway removal to deployment at sea was approximately $30 \mathrm{~min}$.

\section{Behavioral Observations}

After transportation and deployment, it was critical to determine whether the newly transplanted giant clams were behaving normally, opening their valves as needed for feeding and oxygenation.

Since only one wild giant clam had been observed at the control-healthy site, there was concern regarding how resident fish would behave with the newly transplanted giant clams, and whether predation would be significant. Fish species identified as giant clam predators (Neo et al., 2015) had been found in previous surveys at the study sites (Frias-Torres and van de Geer, 2015; Frias-Torres et al., 2015), (Table 1). Therefore, once the giant clams were secured at their target transplant location, small underwater cameras (GoPro) were placed next to the experimental units. The cameras remotely recorded for $3 \mathrm{~h}$ the giant clam valve opening behavior and fish interacting with the clams without human disturbance.

\section{Experimental Design}

To investigate the ability of adult giant clams to survive restoration in the wild, 150 adult Tridacna maxima (4-10 years old) bred in captivity from second-generation brood stock were relocated to the healthy reef (control site) and the restored reef (treatment site) at Cousin Island in two sequential experiments, so survival could be tested with calm (Northwest Monsoon) and rough sea (Southeast Monsoon) conditions at first deployment. The number of clams used was limited to how many individuals the aquaculture facility was willing to donate for each experiment. Specifically, I hypothesized that (1) clams at the healthy reef (control) and the restored reef (treatment) would have the same survival rate, and (2) clam survival would be size-dependent, with larger clams having the highest survival rate.

The first experiment lasted 20 weeks, and 30 clams with a shell length range of 105-188 mm were used. At both the control and treatment sites, 15 clams were deployed on April 11, 2014 at a depth of $12 \mathrm{~m}$. The last monitoring was completed on September 3,2014 . The second experiment lasted 11 weeks. It included 120 clams with a shelf length range of 99-198 $\mathrm{mm}$. At both the control and treatment sites, 60 clams were deployed (30 at $12 \mathrm{~m}$ depth, 30 at $6 \mathrm{~m}$ depth) on June 16, 2014 with last monitoring completed on September 3, 2014. Two fixed $\mathrm{HOBO}^{\circledR}$ water temperature dataloggers at $5 \mathrm{~m}$ and $15 \mathrm{~m}$ depth recorded temperatures every hour with $\pm 0.2^{\circ} \mathrm{C}$ accuracy. During daylight hours 6:00 to 18:00, on April 11, 2014 water temperature was $29.8^{\circ} \mathrm{C}$ (SE 0.06) at $5 \mathrm{~m}$ depth and $29.8^{\circ} \mathrm{C}(\mathrm{SE} 0.01)$ at $15 \mathrm{~m}$ depth. On June 16,2014 water temperature was $27.1^{\circ} \mathrm{C}(\mathrm{SE} 0.02)$ at $5 \mathrm{~m}$ depth and $27.0^{\circ} \mathrm{C}(\mathrm{SE}$ 0.02 ) at $15 \mathrm{~m}$ depth. 
TABLE 1 | Known fish predators of giant clams.

\begin{tabular}{|c|c|c|c|}
\hline \multirow[t]{2}{*}{ Scientific name } & \multirow[t]{2}{*}{ Common name } & \multicolumn{2}{|r|}{ Fish base } \\
\hline & & Trophic level & Food items \\
\hline \multicolumn{4}{|l|}{ BALISTIDAE } \\
\hline Balistapus undulatus & Orange-lined triggerfish & $3.4 \pm 0.42$ & Benthic organisms: algae, echinoderms, fishes, mollusks, tunicates, sponges, hydrozoans \\
\hline Balistoides viridescens* & Titan triggerfish & $3.3 \pm 0.44$ & Sea urchins, coral, crabs, other crustaceans, mollusks, tube worms \\
\hline \multicolumn{4}{|l|}{ LABRIDAE } \\
\hline Cheilinus trilobatus & Tripletail wrasse & $3.5 \pm 0.5$ & Mollusks, crustaceans, fish \\
\hline Halichoeres nebulosus & Nebulous wrasse & $3.4 \pm 0.5$ & $\begin{array}{l}\text { Fish eggs, benthic invertebrates: crabs, sea urchins, ophiuroids, polychaetes, sponges, } \\
\text { mollusks }\end{array}$ \\
\hline \multicolumn{4}{|l|}{ TETRAODONTIDAE } \\
\hline Canthigaster valentini & Black saddled toby & $2.8 \pm 0.30$ & $\begin{array}{l}\text { Filamentous green, brown and coralline red algae, tunicates, corals, bryozoans, polychaetes, } \\
\text { echinoderms, mollusks }\end{array}$ \\
\hline
\end{tabular}

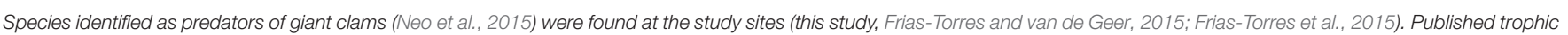

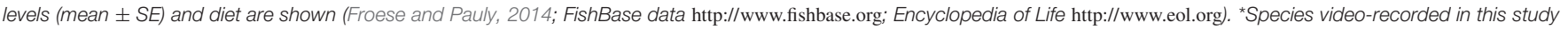
attacking giant clams. Species are ordered taxonomically (Nelson, 2006).

Double-tagging clams allowed individual identification and survival monitoring at close range. However, epibiont attachment, mainly macroalgae and invertebrates, to T. maxima shells (Neo et al., 2015), hindered the ability of divers to locate all giant clams within the reef. To help divers relocate individual clams during the entire field experiments, clams were transplanted in triads, with each clam located at the vertices of an imaginary triangle. Edge length within a triangle ranged from 10 to $60 \mathrm{~cm}$. The distance between triangles ranged from 2.5 to $5.6 \mathrm{~m}$ (Figure 4). Triangle edge length and distance between triangles were measured with and underwater tape to the nearest $\mathrm{cm}$. Clams were wedged in reef and hard bottom crevices, allowing for necessary valve opening and byssum re-attachment. For each triad, clam tag numbers, location within the reef, site (control vs. treatment) and depth (6 vs. $12 \mathrm{~m})$ were recorded and mapped. Individual tagging and mapping of triad location at each reef site facilitated monitoring under field conditions (Figure 5, Supplementary Video 1).

Giant clam survival was monitored once a week or once every 2 weeks, depending on weather conditions. Three types of causes of mortality were quantified: octopus predation, flatworm predation and dislodgement by wave swells. Octopus preyed on clams by adding little rocks to the base of the valves, near the umbo, so the giant clams were unable to close and the octopus had full access to the mantle (Neo et al., 2015; local octopus fishermen Pers. Comm.), leaving the giant clam shells in place, empty with no soft tissue. Flatworms entered the clams through either the byssal orifice or inhalant siphon (Neo et al., 2015), eating the clams from the inside out, leaving shells in place, but with half eaten and decomposed tissue. Strong wave swells dislodged clams, rolled them around the reef, and they eventually were found dead or shell only, away from their deployment location. The actual cause of death after wave swell displacement was unknown.

\section{Statistical Analyses}

Survival analysis (Lee, 1992) based on the Kaplan-Meier function (Zwiener et al., 2011) was used to determine if there were

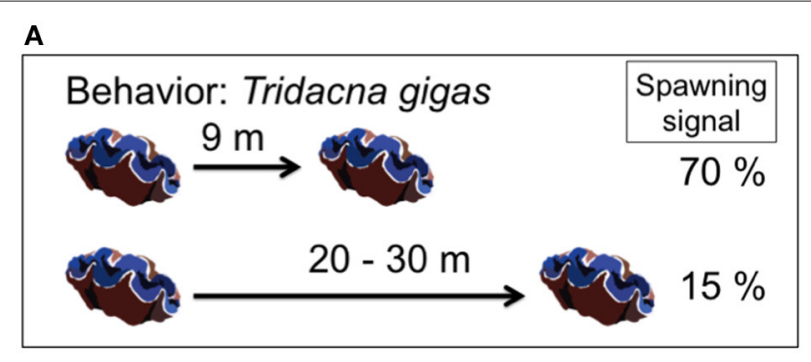

B

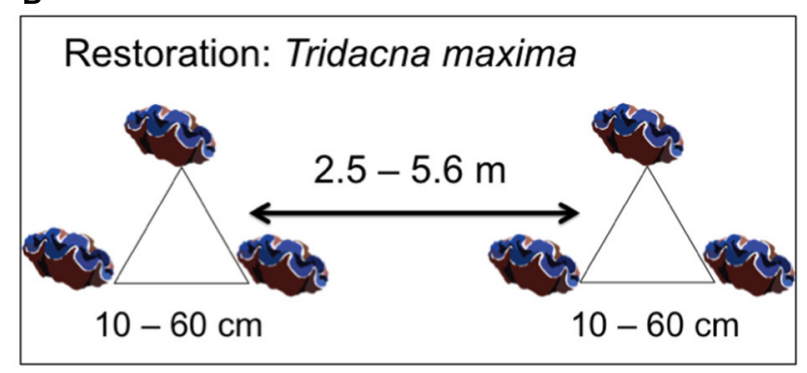

FIGURE 4 | Experimental design. (A) Known spawning behavior in Tridacna gigas shows how distance between individuals and detection of spawning signal are related. (B) The experimental design incorporated the limitations of individual distance and spawning signal detection by deploying T. maxima in triads, and limiting the distance between triads to a maximum of $5.6 \mathrm{~m}$. Credit for giant clam symbols: Woerner (2011).

statistically significant differences in giant clam survival between sites and depths. These statistical techniques originated in clinical trials where human patients received different medical treatments and survival rate was quantified. The Kaplan-Meier function is based on estimating conditional probabilities at each point in time when an event occurs, then taking the product limit of those probabilities to estimate the survival rate at each point in time (Yap, 2004). Here, an "event" is when a transplanted giant clam died. Clams that were still alive at the end of the experiment were "censored" data (equivalent to human patients surviving a clinical trial). Clams that died during the experiment period were 
deemed "uncensored" or "completed" data. The Kaplan-Meier function (Zwiener et al., 2011) was used to calculate survival rates (number of clams alive at the end of the experiment) and the median survival time (the time in each experiment at which half of the clam population had died) differences between the healthy site (control) and the coral transplanted site (treatment) at the 30clam experiment, and between sites and depths at the 120-clam experiment. The log-rank test was used for statistical comparison of survival times between treatments. The different duration of each experiment was due to logistic and funding limitations at the time. To facilitate comparisons between the 20 -week long first experiment and the 11-week long second experiment, survival rates and median survival times for the first experiment were calculated at 11 weeks and at 20 weeks. Differences in survival related to size were evaluated by comparing the length-frequency distributions of giant clams alive at the start and end of each experiment using Kolmogorov-Smirnov tests (K-S test; Conover, 1980), and regression analysis of survival time vs. shell length. All statistical analyses were conducted in Statistica 6.0.
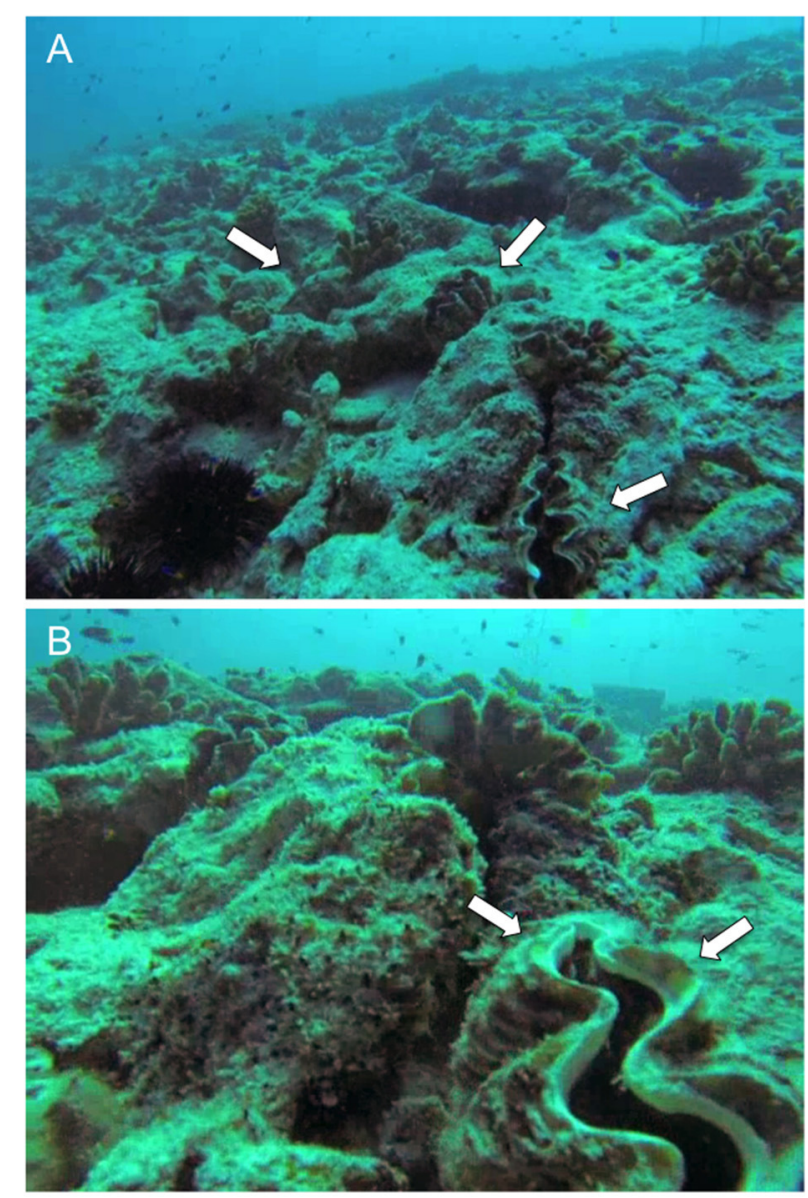

FIGURE 5 | Giant clams (Tridacna maxima) deployed at the coral transplanted site. (A) Triad in a triangle arrangement. White arrows indicate each giant clam. (B) Detail showing glue-on shellfish Hallprint Tags as seen in the field. White arrows show tags. See also Supplementary Video 1.

\section{RESULTS}

Video-recorded observations during the first $3 \mathrm{~h}$ following transplantation revealed the giant clams (Tridacna maxima) opened and closed their valves displaying normal behavior (Supplementary Video 2). Only one Titan Triggerfish (Balistoides viridescens) was recorded attacking two giant clams by ramming against the valves in an attempt to break the shell. (Figure 6, Supplementary Video 3). No other fish species were recorded interacting with the giant clams (Supplementary Video 2).

The survival of transplanted giant clams varied widely as a function of transplant time, site and depth. Based on the KaplanMeier curves, overall survival rate of giant clam transplants ranged between 3.3 and $66.7 \%$. Median survival time ranged from 2 weeks to more than 20 weeks (Tables 2, 3, Figures 7, 8).
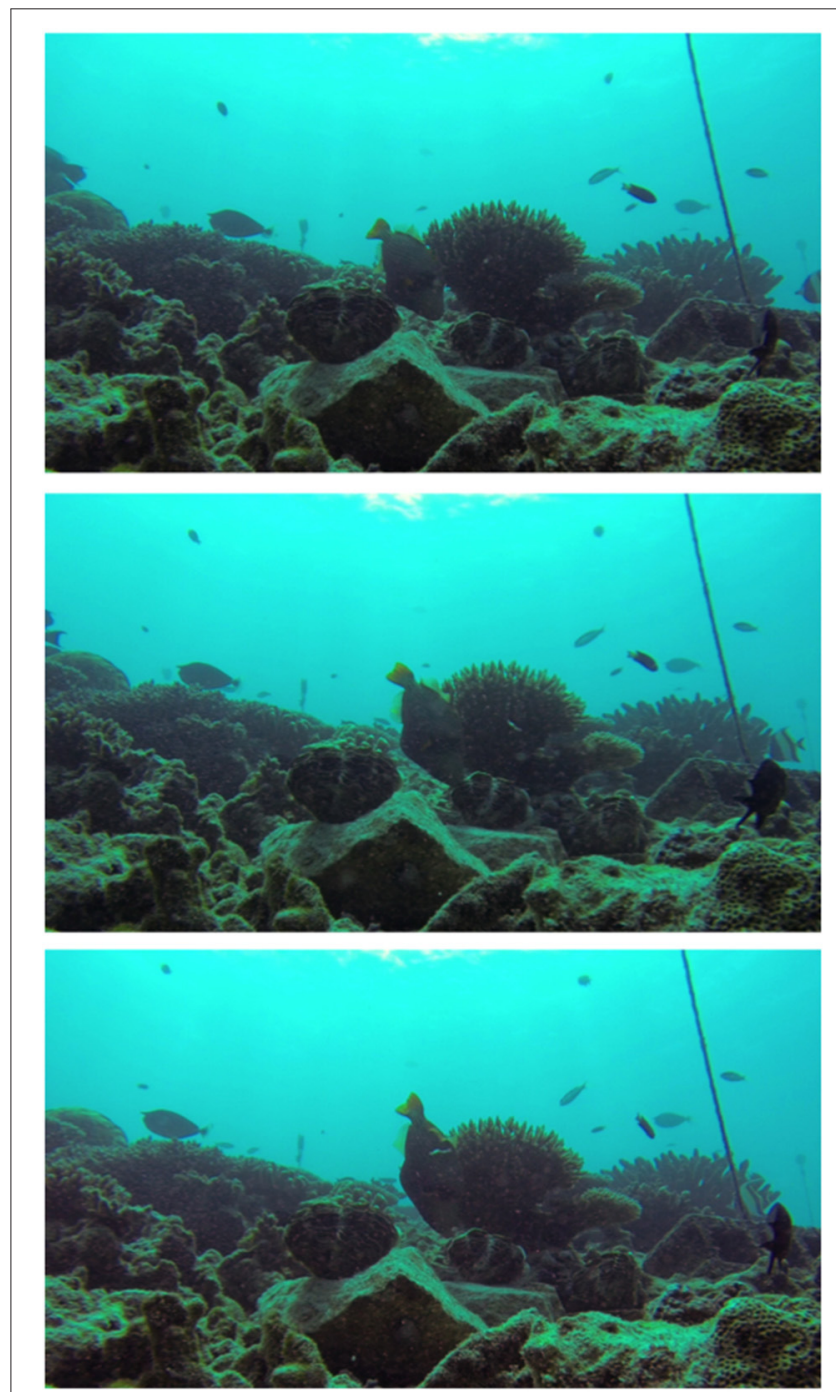

FIGURE 6 | Titan Triggerfish (Balistoides viridescens) attacking Giant Clam (Tridacna maxima). Photo sequence from GoPro underwater video. The fish did not damage the clam. See also Supplementary Videos 2, 3. 
TABLE 2 | Survival analysis for transplanted Giant Clams, Tridacna maxima, during the 30 -clam experiment.

\begin{tabular}{|c|c|c|c|c|}
\hline \multirow[t]{3}{*}{ Kaplan-Meier curve } & \multirow{2}{*}{\multicolumn{2}{|c|}{$\begin{array}{c}\text { Experiment } 1 \\
30 \text {-clams } 11 \text { weeks }\end{array}$}} & \multirow{2}{*}{\multicolumn{2}{|c|}{$\begin{array}{c}\text { Experiment } 1 \\
\text { 30-clams } 20 \text { weeks }\end{array}$}} \\
\hline & & & & \\
\hline & TS & HS & TS & HS \\
\hline Survival rate & $66.7 \%$ & $40 \%$ & $60 \%$ & $26.7 \%$ \\
\hline Median survival time (weeks) & $>11$ & 6 & $>20$ & 6 \\
\hline
\end{tabular}

Results from the Kaplan-Meier curves are shown at 11 weeks and for the full length of the experiment at 20 weeks for the healthy site (control) and coral transplanted site (treatment), both at $12 \mathrm{~m}$ depth. TS, coral transplanted site; HS, healthy site.

TABLE 3 | Survival analysis for transplanted Giant Clams, Tridacna maxima during the 120 -clam experiment.

\begin{tabular}{lcccc}
\hline Kaplan-Meier curve & \multicolumn{4}{c}{ Experiment 2 } \\
\cline { 2 - 5 } & \multicolumn{4}{c}{$\mathbf{1 2 0}$ clams 11 weeks } \\
\cline { 2 - 5 } & TS-6 $\mathbf{~ m}$ & TS-12 $\mathbf{~ m}$ & HS-6 m & HS-12 m \\
\hline Survival rate & $33.3 \%$ & $40 \%$ & $3.3 \%$ & $10 \%$ \\
Median survival time (weeks) & 5 & 10 & 2 & 3 \\
\hline
\end{tabular}

Results from the Kaplan-Meier curves are shown for the healthy site (control) and coral transplanted site (treatment), at $6 \mathrm{~m}$ and $12 \mathrm{~m}$ depth. TS, coral transplanted site; HS, healthy site.

Survival analysis showed that giant clams consistently survived longer at the coral transplanted site (treatment) compared to the healthy site (control) in both the 30-clam experiment [Cox's $F$ test, $F_{(12,22)}=2.605 ; p=0.025$ ] and the 120 clam experiment (Log-rank test, chi-square $=19.94 ; d f=3 ; p=0.00017$ ). In the 30-clam experiment, survival rate at the coral transplanted site was 2.26 times higher than at the healthy site. Median survival time at the coral transplanted site extended beyond the 20 weeks of the experiment. In the 120-clam experiment, survival rate and median survival time were higher at $12 \mathrm{~m}$ than at $3 \mathrm{~m}$ for both sites. At the coral transplanted site, survival rate and median survival time at $12 \mathrm{~m}$ depth were 1.2 times and 2 times higher respectively than at $6 \mathrm{~m}$ depth. At the control healthy site, survival rate and median survival time at $12 \mathrm{~m}$ depth were 3.03 times and 1.5 times higher respectively than at $6 \mathrm{~m}$ depth. In both experiments, median survival time was reached within 11 weeks except for the clams of the first experiment at the treatment site, where $60 \%$ of them were still alive after 20 weeks. When comparing both the 30 -clam and the 120-clam experiments at 11 weeks and $12 \mathrm{~m}$ depth (Tables 2, 3, Figures 7, 8), the control site at the first experiment and the treatment site at the second experiment have the same survival rate of $40 \%$. The treatment site at the first experiment has a survival rate of $66.7 \%$, almost 7 times higher than the control site at the second experiment. In both the 30-clam and 120-clam experiments, there is a protracted mortality stabilization period shown as a horizontal line in the Kaplan-Meier curve. In the 30-clam experiment, the stabilization period is from week 8 to 18 at the control site and from week 9 to 19 at the treatment site (Figure 7). In the 120-clam experiment,
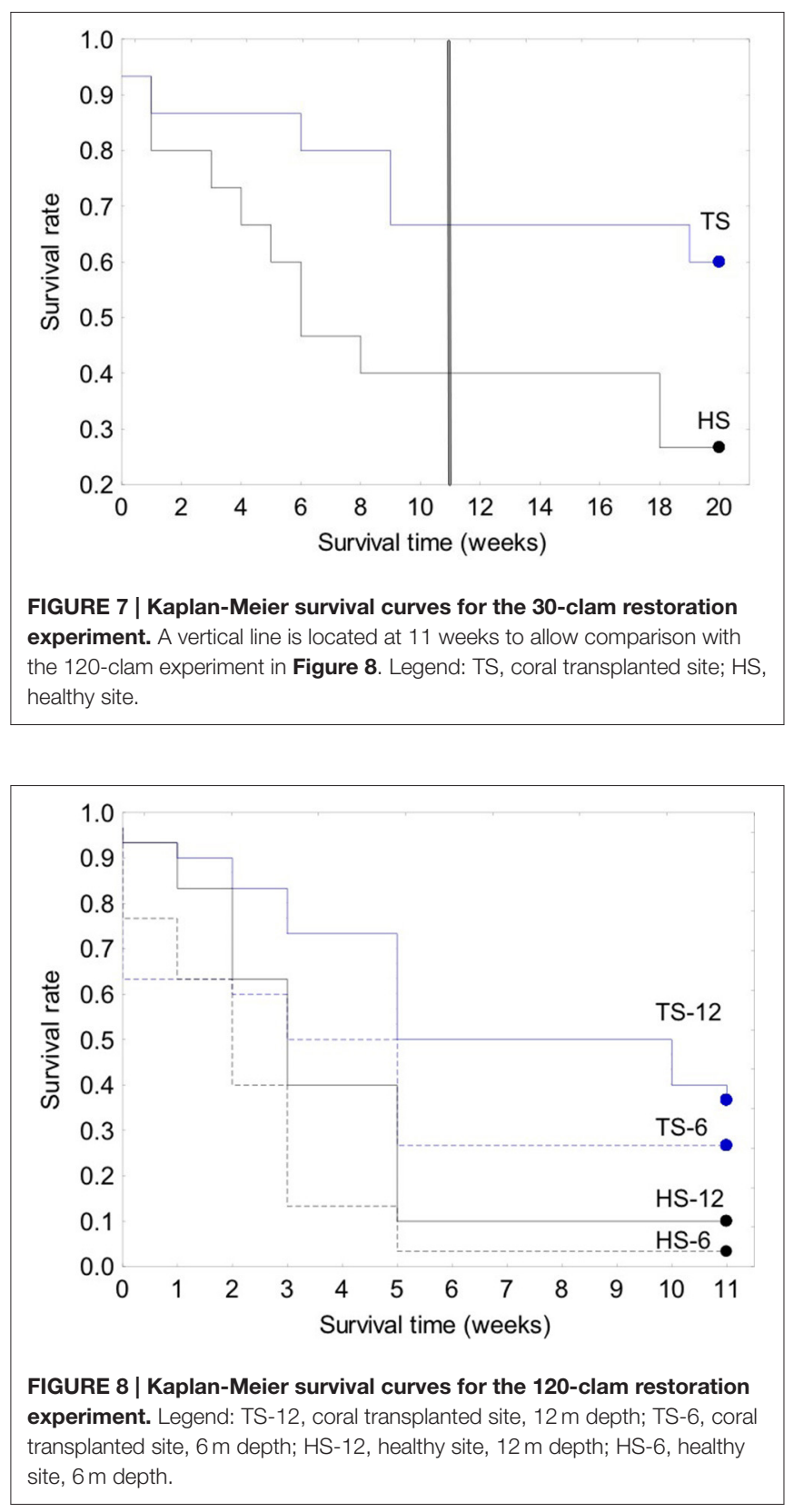

the stabilization period starts at week 5 and lasts until the end of the experiment at 11 weeks, except for the treatment site at $12 \mathrm{~m}$ depth, where it ends at week 10 (Figure 8).

In the 30-clam experiment, all transplant mortality was caused by octopus predation. In the 120-clam experiment, mortality was caused by octopus predation (9.4\%), flatworm predation (6.2\%) and wave swell dislodgement (84.4\%). Survival time did not increase with giant clam size when confronted with octopus predation [30-clam experiment, K-S test, $p>0.05$, Regression $F_{(1,28)}=1.504, R^{2}=0.051, p=0.23$ ], or when confronted with predation by octopus, flatworms and wave swell dislodgement [120-clam experiment, K-S test, $p>0.05$, Regression $\left.F_{(1,118)}=1.56, R^{2}=0.01, p=0.21\right)($ Figures 9, 10). 


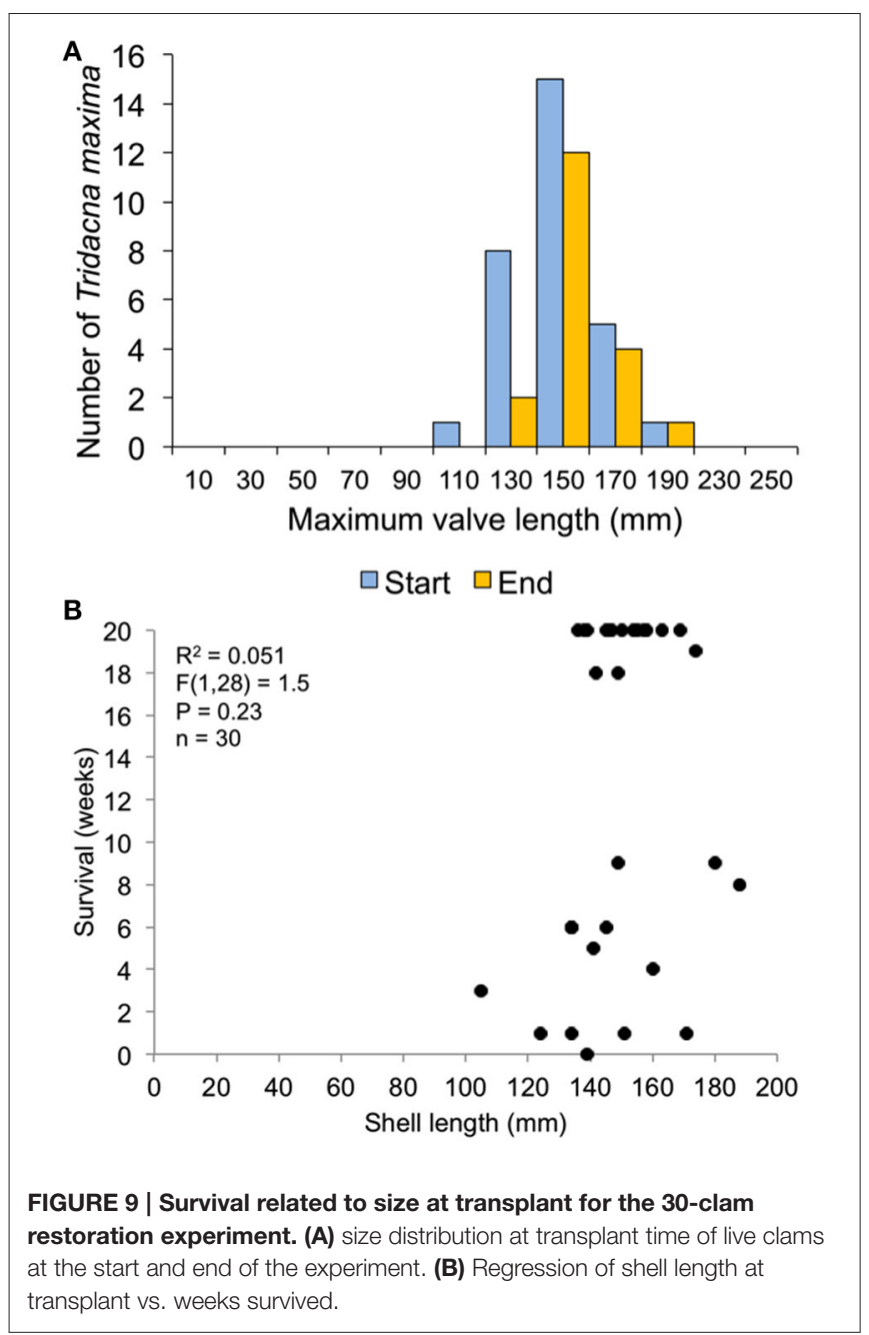

\section{DISCUSSION}

Captive bred adult giant clams (Tridacna maxima) survived transport by boat, deployment to the transplant sites and behaved normally after deployment by opening their valves as expected. During field experiments the video-recorded fish community did not react to the newly transplanted giant clams (Supplementary Video 2), even though the fish community included known predators of giant clams (Table 1). Only the Titan Triggerfish (Balistoides viridescens) was observed attacking the clams without success in an attempt to break their valves (Figure 6, Supplementary Video 3). B. viridescens is capable of crushing calcareous exoskeletons of sessile invertebrates, the aragonite shells of bivalves and it is a known predator of juvenile giant clams (Froese and Pauly, 2014; Frias-Torres and van de Geer, 2015). The transplanted T. maxima were adult individuals with thicker shells than $B$. viridescens had the ability to crush.

Giant clam survival was consistently higher at the coral transplanted site (treatment) than at the healthy site (control) in both experiments. In the first experiment, survival rate was 2.2 times higher at the treatment site than at the control site.

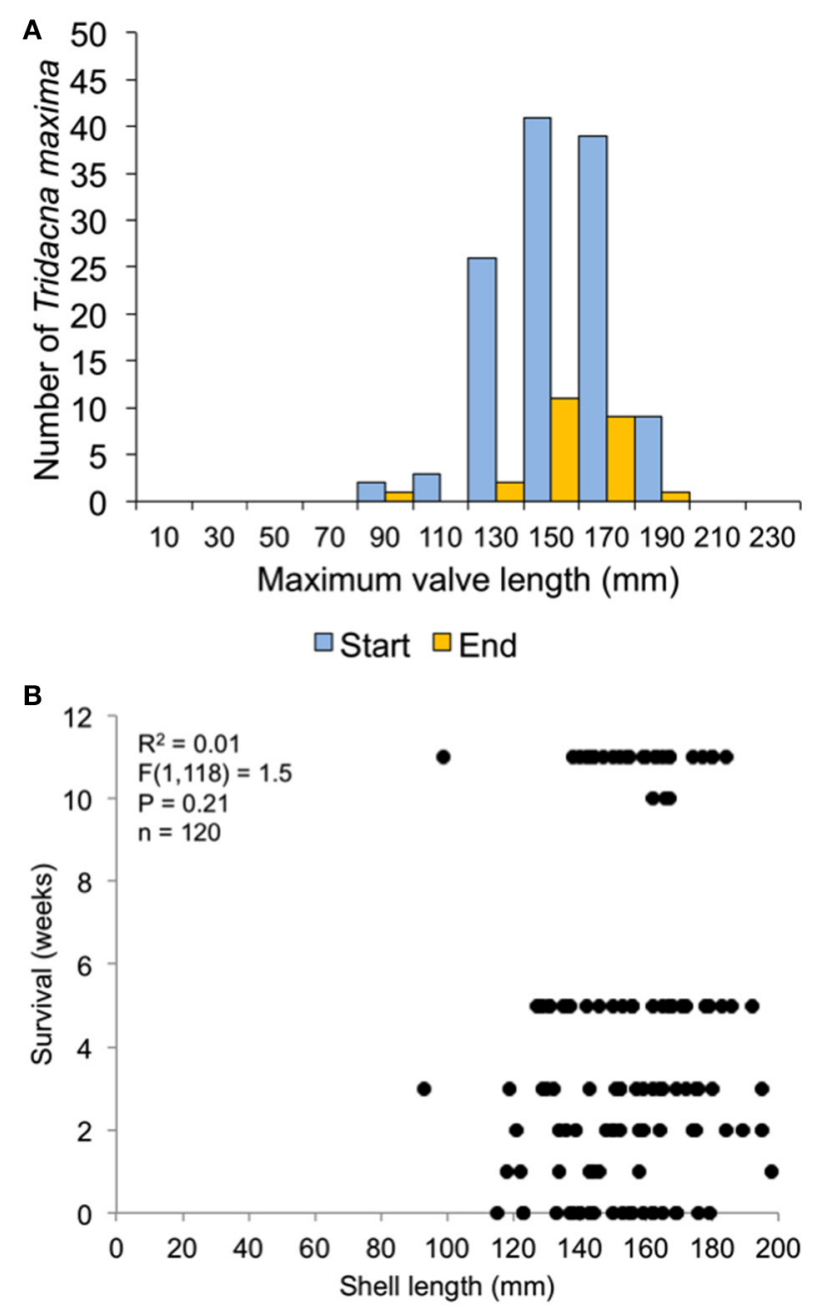

FIGURE 10 | Survival related to size at transplant for the 120-clam restoration experiment. (A) size distribution at transplant time of live clams at the start and end of the experiment. (B) Regression of shell length at transplant vs. weeks survived.

In the second experiment, survival rate was 4-12 times higher at the deep $(12 \mathrm{~m})$ treatment site than at the deep $(12 \mathrm{~m})$ and shallow $(6 \mathrm{~m})$ control sites respectively. In both experiments, median survival time was reached within 11 weeks except for the clams of the first experiment at the treatment site, where $60 \%$ of them were still alive after 20 weeks. When comparing both the 30-clam and the 120-calm experiments at 11 weeks and $12 \mathrm{~m}$ depth (Tables 2, 3), the control site at the first experiment and the treatment site at the second experiment have the same survival rate of $40 \%$. The treatment site at the first experiment has a survival rate of $66.7 \%$, almost 7 times higher than the control site at the second experiment. When comparing the survival rates of the first experiment at 11 weeks and 20 weeks, the treatment site showed only a $6.7 \%$ decrease in survival but the control site showed a further $13.3 \%$ decrease in survival. If the same rates of mortality found in the 30-clam experiment between weeks 11 and 20 would have occurred in the 120 -calm experiment, then, 
no clams would be alive at the control site ( 6 and $12 \mathrm{~m}$ depth), and the treatment site would have a survival rate of 26.6 and $33.3 \%$ at 6 and $12 \mathrm{~m}$ depth respectively. These results suggest that the first 11 weeks are a critical time to monitor post-transplant success when measuring median survival time, and that mortality stabilization (horizontal lines in Figures 7, 8) can offer guidance about the sites and depths with the best survival for transplanted, adult giant clams T. maxima.

Giant clam mortality was likely due to a combination of transplant time of year, predators, byssal re-attachment and wave swells. During the first experiment, giant clam mortality was due to octopus predation and was higher in the healthy site. Transplanted giant clams had no size refuge from octopus predation. Even the largest giant clams in the 105-188 mm SL range (Figure 9) were predated upon due to the octopuses dexterity and intelligence (Montgomery, 2015). The healthy site was a survivor of the $1998 \mathrm{El} \mathrm{Niño} \mathrm{mass} \mathrm{bleaching} \mathrm{event.} \mathrm{It} \mathrm{is}$ an "older" reef compared to the coral transplanted site and has been accumulating corals for a longer time (Montoya-Maya et al., 2016). Therefore, the healthy site provided more potential sites for octopus dens and should have a higher octopus population. The transplant month was critical to ensure clams had enough time to self-attach before heavy swells of the Southeast Monsoon (May to October) began. Giant clams can be toppled by strong waves during storm conditions, even roll laterally for a short distance across the reef, and regain their upright position (Soo and Todd, 2014). In juvenile Tridacna maxima, (1-3 years old) byssal re-attachment occurs within 4 days (Waters et al., 2013). However, captive bred clams demonstrate byssal re-attachment ability diminishes with size and age (A. Hennie, Black Pearl Seychelles, Pers. Comm.) Giant clams transplanted during the first experiment (April) had 1 month to re-attach before the Southeast Monsoon swells began, but clams transplanted in the second experiment (June) were already experiencing the swells during their first month on location in the reef, therefore, mortality during the second experiment was mostly due to dislodgement by wave swells. These results suggest that to maximize survival of adult giant clams, T. maxima, transplant time should occur within the calm season, with a minimum of 1 month before the start of the rough season to allow for byssum re-attachment and at a depth of at least $12 \mathrm{~m}$ to further protect from wave dislodgement.

In giant clam restoration, the juvenile vs. adult trade-off must be considered. In a 6 -week long restoration experiment, 1,2 , and 3 year olds $(9 \mathrm{~mm} \leq \mathrm{SL} \leq 59 \mathrm{~mm})$ captive bred $T$. maxima transplanted to coral bommies had a combined higher survival of $80.6 \%$ when protected inside recruitment enclosures for the first 18 days than the lower survival of $19.6 \%$ when released without protection at the start of the experiment (Cook Islands, Waters et al., 2013). In a 7-month long experiment, 18-month old $T$. squamosa $(80 \mathrm{~mm} \leq \mathrm{SL} \leq 110 \mathrm{~mm}$ ) temporarily transplanted to artificial substrate of ceramic tiles in metal trays had a $80.6 \%$ survival rate without recruitment enclosures (Singapore; Guest et al., 2008). In Palau, survival of multiple cohorts from three size classes of $T$. derasa transplanted to natural substrate was linked to size at transplant, with $0 \%$ survival after 1 day $\left(\mathrm{SL}_{\text {mean }}=12\right.$ $\mathrm{mm}), 89 \%$ survival over 366 days $\left(\mathrm{SL}_{\text {mean }}=130 \mathrm{~mm}\right)$ and $100 \%$ survival after 90 days $\left(\mathrm{SL}_{\text {mean }}=172 \mathrm{~mm}\right.$ ) (Heslinga et al., 1984). Escape size is the size at which tridacnid clams are considered to be free from predation by crush-shell benthic predators and trauma from storm surges and strong currents (Waters et al., 2013). Effective escape size to natural habitats has been reported as $\mathrm{SL}=15 \mathrm{~cm}$ for $T$. derasa (Heslinga et al., 1984), $\mathrm{SL}>20$ $\mathrm{cm}$ for T. gigas, T. derasa and Hippopus hippopus (Gomez and Mingoa-Licuanan, 2006) and SL $=15 \mathrm{~cm}$ for T. squamosal, $H$. hippopus and $H$. porcellanus (Calumpong, 1992). In T. maxima, a SL of $30 \mathrm{~mm}$ has been suggested as a minimum escape size because recruits under this threshold are rarely found in the wild (Yamaguchi, 1977). However, once secured to the substratum, 2 and 3-year-old $T$. maxima SL $\geq 27 \mathrm{~mm}$ are less vulnerable to predation and water turbulence (Waters et al., 2013).

From these previous studies and results from the current study, it appears that transplanting giant clams at or greater than the escape size, regardless of their sexual maturity, is critical to ensure higher survival of transplants. Also, juvenile giant clams have faster byssum re-attachment than adult clams. However, even after reaching escape size, adult giant clams have the advantage of thicker shells to survive attacks from shell-crushing predators, do not require the use of recruitment enclosures and can potentially amplify the restoration effort by production of new sexual recruits.

Results from this study have important implications for the restoration of giant clam populations. Captive bred, adult giant clams, Tridacna maxima, survive release in the wild. Individuals that have reached a size and age unsuitable for economic transportation, in the aquarium trade, can be re-purposed for restoration projects. For adult T. maxima, restoration must occur within the season of lowest wave swell activity to compensate for their reduced ability of byssus re-attachment compared to younger clams. This research demonstrates that observations of animal behavior and an experimental design based on the life history of the species can provide insights on how to achieve successful giant clam restoration. The strong link between individual distance and breeding success in giant clams (Braley, 1984) should be incorporated in ecological restoration design. I recommend such an approach to advance the emerging field of integrative coral reef restoration, where both reef building corals and giant clams are restored in the Indo-Pacific region.

Restoring giant clams should be targeted as an ecosystemwide approach to restore coral reefs in the Indo-Pacific due to the key role they might have as a reservoir of live zooxanthellae, dinoflagelates of the genus Symbiodinium. Both scleractinian corals and tridacnic clams host multiple types of Symbiodinium within single colonies (corals) or individuals (clams) (Baker, 2003). Corals host Symbiodinium as intracellular symbionts in the endodermal cell layer, but tridacnid clams host symbionts within intercellular spaces in the hemal sinuses of the hypertrophied siphon (Trench et al., 1981). Giant clams release large numbers of zooxanthellae in fecal pellets at several orders of magnitude higher than the release rates of corals (Maruyama and Heslinga, 1997). The symbionts defecated by giant clams are morphologically intact and photosynthetically functional (Trench et al., 1981) and become available for other species to "take up," hence contributing to the wider coral reef ecosystem 
(Neo et al., 2015). Similar to scleractinian corals, tridacnid clams bleach (expel their symbionts) during periods of sustained higher than normal water temperature, such as El Niño events. However, tridacnid clam bleaching occurs later than coral bleaching and usually during the most extreme events (Blidberg et al., 2000; Bruno et al., 2001). Giant clams host Symbiodinium clades A, C, and D (DeBoer et al., 2012). Symbiodinium clade D is known as thermally stress-tolerant (Baker et al., 2004; Stat and Gates, 2011), so some resistance to thermal stress in giant clams is possible (Soo and Todd, 2014). Perhaps in bleaching events that only affect corals, giant clams can accelerate the recovery of nearby bleached corals by making live symbionts available through their normal physiological functions. Although giant clams have been largely overfished in many Indo-Pacific coral reefs, the potential synergy between giant clams and corals should be further investigated to better understand coral reef resilience to thermal stress.

\section{ETHICS STATEMENT}

No vertebrates were used in this research. No ethics and protocol approval was required according to national and institutional guidelines. Only captive bred giant clams were used in the field experiments, obtained by Black Pearl Seychelles under an aquaculture agreement with the Government of Seychelles. No wild giant clams were used for the experiments. Bivalves are excluded from the U.S. Animal Welfare Act and from the Seychelles Prevention of Cruelty to Animals Act. However, every effort was made to minimize stress to the giant clams during tagging and transport from the aquaculture facility to the ocean. A field permit was not required to conduct the experiments described at the marine reserve within the Cousin Island Special Reserve. The Special Reserve is managed by Nature Seychelles. As a Nature Seychelles employee at the time, I was able to perform underwater observations and giant clam restoration without the issuing of a specific permit at the no-take marine reserve, as long as I complied with the demands for no damage, harassment or taking of fish or any other marine animal.

\section{AUTHOR CONTRIBUTIONS}

SF conceived and designed the field experiments, developed the giant clam tagging method, performed the field experiments, analyzed the data, contributed materials and analysis tools, wrote

\section{REFERENCES}

Baker, A. C. (2003). Flexibility and specificity in coral-algal symbiosis: diversity, ecology, and biogeography of Symbiodinium. Annu. Rev. Ecol. Evol. Syst. 34, 661-689. doi: 10.1146/annurev.ecolsys.34.011802.132417

Baker, A. C., Starger, C. J., McClanahan, T. R., and Glynn, P. W. (2004). Corals' adaptive response to climate change. Nature 430:741. doi: 10.1038/430741a

Bale, R. (2016). Giant Clam Poaching Wipes Out Reefs in South China Sea. National Geographic Wildlife Watch. Available online at: http://news. nationalgeographic.com/2016/06/south-china-sea-coral-reef-destruction/ (Accessed July 26, 2016). the paper, prepared figures and tables, reviewed drafts of the paper, and submitted the manuscript for publication.

\section{FUNDING}

Funding to Nature Seychelles was received through the United States Agency for International Development (USAID) Reef Rescuers Project 674-A-00-10-00123-00. The funders had no role in study design, data collection and analysis, decision to publish, or preparation of the manuscript. This work was supported in part by the Western Indian Ocean Marine Science Association (WIOMSA), under Grant No. 24/2016 to SF. The views expressed herein are those of the author and do not necessarily reflect the views of WIOMSA and Sida. WIOMSA and Sida are authorized to produce and distribute reprints for educational purposes notwithstanding any copyright notation that may appear herein.

\section{ACKNOWLEDGMENTS}

I thank the Reef Rescuers technical team C. Reveret, K. Rowe, and P. H. Montoya-Maya, and the scientific divers M. Beraud, S. Forestier, H. Goelich, M. Mullins, D. Quinlan, K. Smit, D. Soto, and F. Vidot for their help during strenuous fieldwork; K. Henri and N. Shah for managing the Reef Rescuers project; C. Reveret, N. Hoier and two reviewers for comments on the manuscript; A. Hennie and R. Nilsen at Black Pearl Seychelles for donating the giant clams (Tridacna maxima) needed in this study; D. Hall from Hallprint Tags Australia for donating glue-on shellfish tags needed for this study.

\section{SUPPLEMENTARY MATERIAL}

The Supplementary Material for this article can be found online at: http://journal.frontiersin.org/article/10.3389/fmars. 2017.00097/full\#supplementary-material

Supplementary Video 1 | Locating a triad of tagged giant clams (Tridacna maxima) at the coral transplanted site (treatment site).

Supplementary Video 2 | Fish behavior when encountering newly transplanted giant clams (Tridacna maxima) at the healthy site (control site).

Supplementary Video 3 | A Titan Triggerfish, Balistoides viridescens, attacks a newly transplanted giant clam, Tridacna maxima, at the healthy site (control site). 
clams (Tridacnidae)," in Proceedings 9th International Coral Reef Symposium, 23-27 October (Bali), 561-565.

Braley, R. D. (1984). Reproduction in the giant clams Tridacna gigas and T. derasa in situ on the North Central Great Barrier Reef, Australia, and Papua New Guinea. Coral Reefs 3, 221-227. doi: 10.1007/BF00288258

Bruno, J. F., Siddon, C. E., Witman, J. D., Colin, P. L., and Toscano, M. A. (2001). El Niño related coral bleaching in Palau, Western Caroline Islands. Coral Reefs 20, 127-136. doi: 10.1007/BF00288258

Cabaitan, P. C., Gomez, E. D., and Alino, P. M. (2008). Effects of coral transplantation and giant clam restocking on the structure of fish communities on degraded patch reefs. J. Exp. Mar. Biol. Ecol. 357, 85-98 doi: 10.1016/j.jembe.2008.01.001

Calumpong, H. P. (Ed.) (1992). The Giant Clam: An Ocean Culture Manual. ACIAR Monograph. Canberra: ACIAR.

Conover, W. J. (1980). Practical Nonparametric Statistics, 2nd Edn, New York, NY: John Wiley \& Sons.

DeBoer, T. S., Baker, A. C., Erdmann, M. V., Ambariyanto, Jones, P. R., and Barber, P.H. (2012). Patterns of Symbionidium distribution in three giant clam species across the biodiverse Bird's Head region of Indonesia. Mar. Ecol. Prog. Ser. 444, 117-132. doi: 10.3354/meps09413

Frias-Torres, S., Goehlich, H., Reveret, C., and Montoya-Maya, P. H. (2015). Reef fishes recruited at midwater coral nurseries consume biofouling and reduce cleaning time in Seychelles, Indian ocean. Afr. J. Mar. Sci. 37, 421-426. doi: 10.2989/1814232X.2015.1078259

Frias-Torres, S., and van de Geer, C. (2015). Testing animal-assisted cleaning prior to transplantation in coral reef restoration. Peer J. 3:e1287. doi: $10.7717 /$ peerj. 1287

Froese, R., and Pauly, D. (eds.) (2014). FishBase. Available online at: http://www.fishbase.org (Accessed July 25, 2016).

Gilbert, A., Andréfouët, S., Yan, L., and Remoissenet, G. (2006). The giant clam Tridacna maxima communities of three French Polynesia islands: comparison of their population sizes and structures at early stages of their exploitation. ICES J. Mar. Sci. 63, 1573-1589. doi: 10.1016/j.icesjms.2006.07.001

Gomez, E. D., Mingoa-Licuanan, S., and Roa-Quaoit, H. A. (2000). "The culture of the true giant clam Tridacna gigas for conservation in the Philippines," in Conference Proceedings: Special Session on Mollusk Research in Asia (Los Baños: University of the Philippines), 159-163

Gomez, E. D., and Mingoa-Licuanan, S. S. (2006). Achievements and lessons learned in restocking giant clams in the Philippines. Fish. Res. 80, 46-52. doi: 10.1016/j.fishres.2006.03.017

Guest, J. R., Todd, P. A., Goh, E., Sivaloganathan, B., and Reddy, K. P. (2008). Can giant clam (Tridacna squamosa) populations be restored on Singapore's heavily impacted coral reefs? Aquat. Conserv. Mar. Freshwater Ecosyst. 18, 570-579. doi: $10.1002 /$ aqc. 888

Heslinga, G., Perron, F. E., and Orak, O. (1984). Mass culture of giant clams (F. Tridacnidae) in Palau. Aquaculture 39, 197-215. doi: 10.1016/00448486(84)90266-7

IUCN (2016). IUCN Red List of Threatened Species. Available online at: www.IUCNredlist.org (Accessed December 8, 2016).

Jackson, L. E., Barrie, J. V., Forbes, D. L., Shaw, J., Manson, G. K., and Schmidt, M. (2005). Effects of the 26 December 2004 Indian Ocean tsunami in the Republic of Seychelles. Report of the Canada UNESCO Indian Ocean Tsunami Expedition, 19 January-5 February 2005. Geol. Surv. Can. 4539:73. Avilable online at: http://www.unisdr.org/files/2193_VL323132.pdf

Jantzen, C., Wild, C., El-Zibdah, M., Roa-Quiaoit, H., Haacke, C., and Richter, C. (2008). Photosynthetic performance of giant clams, Tridacna maxima and T. squamosa, Red Sea. Mar. Biol. 155, 211-221. doi: 10.1007/s00227-008-1019-7

Jones, D. S., Williams, D. F., and Romanek, C. S. (1986). Life history of symbiont-bearing giant clams from stable isotope profiles. Science 231, 46-48. doi: $10.1126 /$ science. 231.4733 .46

Larson, C. (2016). Shell trade pushes giant clams to the brink. Science 351, 323-324 doi: 10.1126/science.351.6271.323

Lee, E. T. (1992). Statistical Methods for Survival Data Analysis, 2nd Edn., New York, NY: Wiley Interscience Publication.

Lucas, J. S. (1988). "Giant clams: description, distribution and life history," in Giant clams in Asia and the Pacific, eds J. W. Copland and J. S. Lucas (Canberra, ACT: Australian Centre for International Agricultural Research), 21-32.
Lucas, J. S. (1994). The biology, exploitation, and mariculture of giant clams (Tridacnidae). Rev. Fish. Sci. 2, 181-223. doi: 10.1080/10641269409388557

Maruyama, T., and Heslinga, G. A. (1997). Fecal discharge of zooxanthellae in the giant clam Tridacna derasa, with reference to their in situ growth rate. Mar. Biol. 127, 473-477. doi: 10.1007/s002270050035

McMurray, S. E., and Pawlik, J. R. (2009). A novel technique for the reattachment of large coral reef sponges. Restor. Ecol. 17, 192-195. doi: 10.1111/j.1526100X.2008.00463.x

Montgomery, S. (2015). The Soul of an Octopus: A Surprising Exploration into the Wonder of Consciousness. New York, NY: Atria Books.

Montoya-Maya, P. H., Smit, K. P., Burt, A. J., and Frias-Torres, S. (2016). Large scale coral reef restoration could assist natural recovery in Seychelles, Indian ocean. Nat. Conserv. 16, 1-17. doi: 10.3897/natureconservation. 16.8604

Munro, J. L. (1993). "Giant Clams," in Nearshore Marine Resources of the South Pacific: Information for Fisheries Development and Management, eds A. Wright and L. Hill (Suva: Institute of Pacific Studies; Forum Fisheries Agency; Honiara and International Centre for Ocean Development), 431-449.

Nelson, J. S. (2006). Fishes of the World, 4th Edn. Hoboken, NJ: John Wiley \& Sons.

Neo, M. L., Eckman, W., Vicentuan, K., Teo, S. L. M., and Todd, P. A. (2015). The ecological significance of giants clams in coral reef ecosystems. Biol. Conserv. 181, 111-123. doi: 10.1016/j.biocon.2014.11.004

Neo, M. L., and Todd, P. A. (2012). Giant clams (Mollusca: Bivalvia: Tridacninae) in Singapore: history, research and conservation. Raff. Bull. Zool. 25, 67-78. Avilable online at: http://lkcnhm.nus.edu.sg/nus/index.php/supplements/12research/research-publications/249-supplement-no-25

Newman, W. A., and Gomez, E. D. (2000). "On the status of giant clams, relics of Tethys (Mollusca: Bivalvia: Tridacnidae)," in Proceedings of the Ninth International Coral Reef Symposium, Vol. 2. (Bali), 927-936.

Precht, W. F. (ed.) (2006). Coral Reef Restoration Handbook. Boca Raton, FL: CRC Press.

Soo, P., and Todd, P. A. (2014). The behaviour of giant clams (Bivalvia: Cardiidae: Tridacninae). Mar. Biol. 161, 2699-2717 doi: 10.1007/s00227-014-2545-0

Spalding, M. D., and Jarvis, G. E. (2002). The impact of the 1998 coral mortality on reef fish communities in the Seychelles. Mar. Poll. Bull. 44, 309-321. doi: 10.1016/S0025-326X(01)00281-8

Spencer, T., Teleki, K. A., Bradshaw, C., and Spalding, M. D. (2000). Coral bleaching in the southern Seychelles during the 1997-1998 Indian Ocean warm event. Mar. Poll. Bull. 40, 569-586. doi: 10.1016/S0025-326X(00)00026-6

Stat, M., and Gates, R. D. (2011). Clade D Symbiodinium in scleractinian corals: a "nugget" of hope, a selfish opportunist, an ominous sign, or all of the above? J. Mar. Biol. 2011:730715. doi: 10.1155/2011/730715

Suding, K., Higgs, E., Palmer, M., Callicott, J. B., Anderson, C. B., Baker, M., et al. (2015). Committing to ecological restoration. Science 348, 638-640. doi: $10.1126 /$ science.aaa4216

Tisdell, C., and Menz, K. M. (1992). "Giant clam farming and sustainable development: an overview," in Giant Clams in the Sustainable Development of the South Pacific: Socioeconomic Issues in Mariculture and Conservation, ed C. Tisdell (Canberra, ACT: ACIAR), 3-14.

Tomascik, T., Mah, A. J., Nontji, A., and Moosa, M. K. (1997). The Ecology of the Indonesian Seas: Part One. Hong Kong: Periplus Editions.

Travis, W. (1990). Beyond the Reefs and Shark for Sale: Adventures in the Seychelles. Mahe: Calusa Bay Publications.

Trench, R. K., Wethey, D. S., and Porter, J. W. (1981). Observations on the symbiosis with zooxanthellae among the Tridacnidae (Mollusca, Bivalvia). Biol. Bull. 161, 180-198. doi: 10.2307/1541117

UNEP-WCMC. (2016). Convention on International Trade in Endangered Species of Wild Fauna and Flora. Available online at: www.cites.org (Accessed December 8, 2016).

Wabnitz, C., Taylor, M., Green, E., and Razak, T. (2003). From Ocean to Aquarium. The Global Trade in Marine Ornamental Species. Cambridge: UNEPWCMC.

Wada, S. K. (1952). Protandric functional hermaphroditism in the tridacnid clams. Oceanogr. Mag. 4, 23-30.

Waters, C. G., Story, R., and Costello, M. J. (2013). A methodology for recruiting a giant clam, Tridacna maxima, directly to natural substrata: a first step in reversing functional extinctions? Biol. Conserv. 160, 19-24. doi: 10.1016/j.biocon.2012.12.036 
Wells, S. M. (1997). Giant Clams: Status, Trade and Mariculture, and the Role of Cites in Management. Gland; Cambridge: IUCN-The World Conservation Union.

Woerner, J. (2011). Integration and Application Network. University of Maryland Center for Environmental Science. Available online at: http://ian.umces.edu/ imagelibrary/

WoRMS Editorial Board (2017). World Register of Marine Species. Available onliine at: http://www.marinespecies.org at VLIZ (Accessed February 18, 2017).

Yamaguchi, M. (1977). Conservation and cultivation of giant clams in the tropical pacific. Biol. Conserv. 11, 13-20.

Yap, H. T. (2004). Differential survival of coral transplants on various substrates under elevated water temperatures. Mar. Pollut. Bull. 49, 306-312. doi: 10.1016/j.marpolbul.2004.02.017
Zwiener, I., Blettner, M., and Hommel, G. (2011). Survival analysis. Dtsch. Arztebl. Int. 108, 163-169. doi: 10.3238/arztebl.2011.0163

Conflict of Interest Statement: The author declares that the research was conducted in the absence of any commercial or financial relationships that could be construed as a potential conflict of interest.

Copyright $\odot 2017$ Frias-Torres. This is an open-access article distributed under the terms of the Creative Commons Attribution License (CC BY). The use, distribution or reproduction in other forums is permitted, provided the original author(s) or licensor are credited and that the original publication in this journal is cited, in accordance with accepted academic practice. No use, distribution or reproduction is permitted which does not comply with these terms. 